Michael Y. Bennett*

\title{
Propositions in theatre: Theatrical utterances as events
}

https://doi.org/10.1515/jls-2018-2004

\begin{abstract}
Using William Shakespeare's Hamlet and the play-within-the play, The Murder of Gonzago, as a case study, this essay argues that theatrical utterances constitute a special case of language usage not previously elucidated: the utterance of a statement with propositional content in theatre functions as an event. In short, the propositional content of a particular $\mathrm{p}$ (e.g. $\mathrm{p}_{1}, \mathrm{p}_{2}, \mathrm{p}_{3} \ldots$...), whether or not it is true, is only understood-and understood to be true-if $\mathrm{p}_{1}$ is uttered in a particular time, place, and situation (i.e. during a theatrical event); otherwise, the propositional content in those theatrical utterances can either be false or contingently true.
\end{abstract}

Keywords: theatrical utterance, propositional instability, events

In the most basic and obvious sense, some words function as subjects, some as predicates, other words function as prepositions, as modals, and others as indexicals. J. L. Austin's "performatives"-e.g. "I now pronounce you man and wife" and "I name this ship 'The Queen Mary"--were revolutionary because the propositions in these statements offered an alternative to the dichotomous truth value of a statement that preoccupied the logical positivists, as these propositions are neither "true" nor "false," but perform a function of some sort. I only open with Austin's now-defunct notion of "performatives" not because I want to engage with Austin's performatives at all, but because Austin used "performatives" to demonstrate a special case of language usage that, at the time, had not yet been considered and/or elucidated. I am only interested in Austin to analogously note that there is another specific situation where the utterance of propositions has a function that has similarly not yet been elucidated. In short, some theatrical utterances constitute a special case of language usage: I argue that utterances of statements with propositional content in theatre function as events.

*Corresponding author: Michael Y. Bennett, Department of English, University of WisconsinWhitewater, Whitewater, WI USA, E-mail: bennettm@uww.edu 


\section{Speech act theory and events}

There is a vast field of study about events, but almost-without-exception, the focus of philosophers and linguists (and all in between, or beyond) is on defining what is an event or how to refer to an event. ${ }^{1}$ That is, the two main questions pondered are, 1) how do we describe the ontology of an event? And/or 2) how do we describe and/or understand the language about, or referring to, an event? These two questions are asked about events that broadly fall into the realm of actions or states. But what if the utterance of statement containing a proposition is an event itself? Theatrical language is a special case of language usage that offers the philosopher, linguist, and literary/arts critic (all broadly defined) a different angle to consider thinking about both what an event is and how to describe an event.

Even more basic to playtexts and the logic of theatre, there exists a presumption, regardless of the naturalness or experimental nature of the language within a play, that the language within a play operates in the same manner that it does in our world. This is not the case, though, in theatre. The two closest corollaries to the language in theatre are 1) metaphor and 2) sarcasm. Both metaphor (and allegory, too) and sarcasm discuss one thing, but yet mean/ intend something else. Theatrical language, too, has this same function and works on two levels, as well. But, by and large, the speeches (and their propositional contents) in playtexts are not written or uttered metaphors, nor are they are saying the exact opposite of what is said (as in sarcasm). Instead, unlike sarcasm, where the opposite of what is uttered is meant, and also unlike in metaphor, which similarly works on two levels-one the literal understanding of the utterance and one the figurative interpretation of the utterance-the utterance of propositional content in theatre is tripartite: 1) an utterance in theatre, is a subject/predicate of an unpronounced indexical pointing to a specific state of affairs, 2) performs a function in that the counterfactual condition is projected forward in the type of response/action, and 3) is a part, functions as, or is the event, itself, that the audience is there to witness. There is a fourth element, too, and that is that metaphorical interpretation is the outgrowth of the tripartite structure.

\footnotetext{
1 Fabio Pianesi and Achille C. Varzi suggest that the field on events can be broken down into the following general groups of focus: events as universals; events as particulars; the indeterminacy and vagueness of speaking about events; the logical form of names of and propositions about events; that the semantics of events could be extended to discuss states; and linguistic applications regarding events (Speaking of Events, Fabio Pianesi, et al., eds. [Oxford: Oxford University Press, 2000]), 3-47.
} 
The artifice of theatre is that the propositional content contained in the playtext functions as an extended indexical that directs us/situates us/points to an extended counterfactual condition, which is the fictional world of the play. The reality of theatre, however, is that the utterances of the propositional content in statements contained in the playtext function as and are the event of theatre. That is, the words and statements that create and constitute the propositional content of theatrical utterances in theatre function as subjects, predicates, as modals, etc. within the fictional world of the play. However, outside of the world of the play-to the audience-the utterances of the propositions contained in theatrical statements function as, and are, the theatrical event, itself.

\section{2 "Strike three. you're out!"}

Before I get to language in theatre, I want to take you out to a ballgame. Language in baseball provides a good example to build a transitory bridge to the language in the theatre. Referees at professional sporting events, especially obvious in the case of umpires in baseball, use language that has three functions (of course, used in the context of a baseball game and spoken by the umpires). "Ball," "Strike," and “Out" 1) function as in ordinary language as predicates of an unpronounced indexical; 2) are utterances that perform a function in the game, and 3) furthermore, function as (a part of) the event.

For example, first, when the Homeplate Umpire at a baseball game calls "Ball," "Ball" functions as a predicate of an unpronounced indexical which (though unstated) points to a specific state of affairs (i.e. "This is a ball." That is, the ball thrown by the pitcher did not pass over homeplate and through the strike zone). Second, the utterance of "Ball" is not only a predicate (or even functions in some way as an indexical) that attempts to describe a specific state of affairs; in addition the call of "Ball" performs a function in the game, affecting the future performance and playing out of the game. Furthermore, the umpiring of a sporting event is a part of, a function of, and is, the sporting event itself as well.

\section{Theatre: moveable referents}

Elsewhere I have discussed theatrical language and interpretation, suggesting that there is a "moveable limit" in interpretation between dramatic text and theatrical performance: 
... a dramatic text [...] essentially constitutes a moveable limit because since a dramatic text is a somewhat incomplete artistic expression because, as I suggest in the relatively simple statement, in the theatre (in general),

(Character) A intends (Character) B to understand $p$, but the audience-through the utterance of $p$-who also understands $p$, understands an open-ended $q$, as well.

Interpretation, then-even if it were possible to experience the exact same reality-will be wildly varied, and, thus, while the words do not change (though, sometimes plays are later edited), the contexts and readers of those words do, and thus, there is an inherent stability with the utterances of $p$, but there is instability in the referents associated with $q{ }^{2}$

Using the above notions of theatrical language, in William Shakespeare's Hamlet, the focus is not on the play-within-the-play-i.e. the focus is not on The Murder of Gonzago within Hamlet-that is, not on the $p$ in the play-withinthe-play, but the focus is on the $q$ derived from The Murder of Gonzago, or the $q$ the way that Claudius interprets it. Hamlet's purpose in having the Players stage The Murder of Gonzago, is in no way to have the audience, and most particularly Claudius, hear and take in the $p$. Hamlet's sole intention is for Claudius to take away the $q$. This is the case for the audience of the play, Hamlet, as well.

Kent Bach claims that a speech act comprises a multiplicity of actions, each corresponding to a different one within a set of intentions. When words are used on stage (e.g. when an actor is using them as part of his or her performance in Hamlet), they should be related to a higher-level speech act. In fiction, as Deirdre Wilson says:

... an author may be simultaneously performing acts of communication on two different levels: a lower-level act of describing a fictional world, and a higher-level act of showing this world to the reader as an example of what is possible, or conceivable. ${ }^{3}$

We can say then that the utterance of the propositional content of the playwithin-the-play is a low-level speech act in that it describes the fictional world of The Murder of Gonzago, which yields a high-level speech act wherein Claudius understands that the play is analogous to his own situation and that Hamlet is in the know. However, while $p$ (i.e. the low-level speech act of describing a

2 Michael Y. Bennett, Analytic Philosophy and the World of the Play (London and New York: Routledge, 2017), 63-64. These observations are made in a larger conversation referencing "Leibniz's Law" where a theatrical performance must necessarily, because of the change in medium, be different than the dramatic text, and thus, performance is not merely a reproduction of an original.

3 D. Wilson (2011), "Relevance and the Interpretation of Literary Works”, UCL Working Papers in Linguistics 23: 69-80. < http://www.ucl.ac.uk/psychlangsci/research/linguistics/publications/ uclwpl23>77. See also, K. Bach (2003) "Speech acts", Routledge Encyclopedia of Philosophy (London: Routledge). 
fictional state of affairs) is stable and $q$ (i.e. the high-level speech act of interpretation) is moveable, the audience does not need to understand $q$ for this to be an event. That is, while the audience of Hamlet is focused on Claudius' understanding of the high-level speech act, the other spectators (i.e. the other characters) in the world of Hamlet are witnessing The Murder of Gonzago, but these other characters on stage (in Hamlet) are not privy to the same information that Claudius (and Hamlet and Horatio) possesses.

Brand (1976) argues that events are spatio-temporal particulars. ${ }^{4}$ Thinking about the two plays, Hamlet and The Murder of Gonzago (the latter, the play within Hamlet), the utterance of a $p_{1}$-e.g. Marcellus saying "Something is rotten in the state of Denmark" to Horatio (Hamlet 1.4)-does not convey the same propositional content, the same $p_{1}$, to the receiver of those utterances (i.e. Horatio) as to the audience members watching Hamlet. That is, the proposition that there is something rotten in Denmark, now (as in, in the fictional time and world of the play), is what is being communicated to Horatio. But the "now" is all important, as "Something is rotten in the state of Denmark" is a proposition stated in the present (i.e. using the present participle), but in the context of the rest of the propositions in Hamlet, the $p s$ (e.g. $p_{2}, p_{3}, p_{4}, p_{5} \ldots$ ) in the play, and in the context of the gathering of an audience at a particular time and a particular place, the audience understands an open-ended $q_{1}$.

In the case of the Marcellus's utterance of $p_{1}$ in the particular spatio-temporal situation (i.e. the speaker, the actor playing Marcellus saying $p_{1}$ to the receiver, the actor playing Horatio, in front of an audience), the audience understands $q_{1}$, where $q_{1}$ is that there is something corrupt unfolding in the Danish court, the world of the play, the fictional world of Hamlet. The utterance of $p_{1}$ is an integral part of the theatrical event. However, the propositional content of $p_{1}$ can either be false or contingently true outside of the world of the play (even as used in the above metaphorical sense, as Denmark is not known to be a corrupt and unethical nation, now). In short, the propositional content of a particular theatrical statement, e.g. $p_{1}, p_{2}, p_{3} \ldots$, whether or not it is true, is only understood, and understood to be true, if $p_{1}$ is uttered in a particular time, place, and situation (i.e. during a theatrical event).

If the point of a play is for an audience to understand the propositional contents of a moveable, instable $q$, within a spatio-temporal particular (the event of the theatrical performance), $p_{1}$ (or $p_{2}$ or $p_{3} \ldots$ ) is not only an integral part of the spatio-temporal particular which will not stand on its own (as these propositions can be either false or contingently true), but $p_{1}$, furthermore, though

4 M. Brand, "Particulars, Events, and Actions," Action Theory: Proceedings of the Winnipeg Conference on Human Action, eds. M. Brand and D. Walton (Dordrecht: Reidel, 1976), pp. 133-158. 
apparently universal as the utterance of $p$, will take place in every faithful performance of Shakespeare's Hamlet for eternity. However, because of the particular nature of afternoon or nightly performances (i.e. the performance of William Shakespeare's Hamlet on a given afternoon or night by a given group of actors in front of a given group of audience members), the propositional content of $p$ (i.e. the propositional content of the play, Hamlet) and the propositional content of all of the utterances of statements within Hamlet (i.e. all of the statements in the play with propositional content [i.e. $\left.p_{1}, p_{2}, p_{3}, \ldots\right]$ ) will forever remain unstable because of the changes among the composition of actors and audience members and differences across different locations and eras.

Acknowledgements: I would like to thank the two anonymous JLS reviewers for their invaluable feedback, much of which is incorporated into this essay, either directly or indirectly. 